\title{
Medical Tourism for CCSVI Procedures in People with Multiple Sclerosis: An Observational Study
}

\author{
Luanne M. Metz, Jamie Greenfield, Ruth Ann Marrie, Nathalie Jette, \\ Gregg Blevins, Lawrence W. Svenson, Katayoun Alikhani, Winona Wall, \\ Raveena Dhaliwal, Oksana Suchowersky
}

\begin{abstract}
Background: Many Canadians with multiple sclerosis (MS) have recently travelled internationally to have procedures for a putative condition called chronic cerebrospinal venous insufficiency (CCSVI). Here, we describe where and when they went and describe the baseline characteristics of persons with MS who participated in this non-evidence-based medical tourism for CCSVI procedures. Methods: We conducted a longitudinal observational study that used online questionnaires to collect patient-reported information about the safety, experiences, and outcomes following procedures for CCSVI. A convenience sample of all Albertans with MS was recruited between July 2011 and March 2013. Results: In total, 868 individuals enrolled; 704 were included in this cross-sectional, baseline analysis. Of these, 128 (18.2\%) participants retrospectively reported having procedures for CCSVI between April 2010 and September 2012 . The proportion of participants reporting CCSVI procedures declined from 80 (62.5\%) in 2010, to 40 (31.1\%) in 2011, and 8 (6.3\%) in 2012. In multivariable logistic regression analysis, CCSVI procedures were independently associated with longer disease duration, secondary progressive clinical course, and greater disability status. Conclusions: Although all types of people with MS pursued procedures for CCSVI, a major driver of participation was greater disability. This highlights that those with the greatest disability are the most vulnerable to unproven experimental procedures. Participation in CCSVI procedures waned over time possibly reflecting unmet expectations of treated patients, decreased media attention, or that individuals who wanted procedures had them soon after the CCSVI hypothesis was widely publicized.
\end{abstract}

RÉSUMÉ: Étude observationnelle du tourisme médical pour des interventions pour IVCSC par des individus atteints de SP. Contexte: Plusieurs Canadiens atteints de sclérose en plaques (SP) se sont rendus dans différents pays pour subir une intervention visant à traiter une prétendue insuffisance veineuse cérébrospinale chronique (IVCSC). Nous rapportons où et quand ils sont allés ainsi que les caractéristiques initiales des individus atteints de SP qui ont participé à ce tourisme médical pour y subir cette intervention non fondée sur des données probantes. Méthode: Nous avons effectué une étude observationnelle longitudinale au moyen de questionnaires en ligne pour recueillir de l'information de ces patients sur la sécurité, les expériences et les résultats suite à des interventions pour IVCSC. Un échantillon de commodité de tous les Albertains atteints de SP a été recruté entre juillet 2011 et mars 2013. Résultats: En tout, 868 individus se sont inscrits et 704 ont été inclus dans l'analyse transversale des données initiales. Parmi eux, 128 participants $(18,2 \%)$ ont rapporté rétrospectivement avoir subi des interventions pour IVCSC entre avril 2010 et septembre 2012. Le nombre des participants qui ont rapporté avoir subi ces interventions a diminué de 80 (62,5\%) en 2010 à 40 (31\%) en 2011 et à 8 (6,3\%) en2012. L'analyse de régression logistique multivariée a montré que les interventions pour IVCSC étaient associées de façon indépendante à une durée plus longue de la maladie, à une forme secondaire progressive au point de vue évolution clinique et à un niveau d'invalidité plus important. Conclusions: Bien que des individus de tous types atteints de SP aient eu recours à des interventions pour IVCSC, un niveau de handicap plus sévère constituait un facteur déterminant de cette décision. Ceci souligne le fait que ceux qui ont un plus haut degré d'invalidité sont les plus vulnérables quand il s'agit d'interventions expérimentales dont l'efficacité n'a pas été démontrée. La participation à des interventions pour IVCSC a diminué avec le temps, ce qui reflète possiblement la déception des patients n'ayant pas bénéficié des résultats escomptés, une diminution de l'exposition dans les médias ou que les individus qui voulaient subir l'intervention l'ont subi peu après que l'hypothèse de l'IVCSC ait été largement médiatisée.

Keywords: CCSVI, medical tourism, multiple sclerosis

doi:10.1017/cjn.2015.350

Can J Neurol Sci. 2016; 43: 360-367

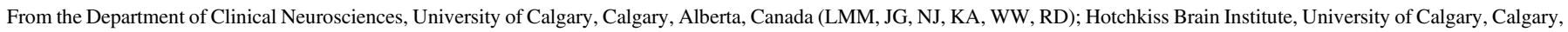
Alberta, Canada (LMM, JG, NJ, KA, WW, RD); Departments of Internal Medicine and Community Health Sciences, University of Manitoba, Winnipeg, Manitoba, Canada (RAM);

Department of Community Health Sciences, University of Calgary, Calgary, Alberta, Canada (NJ, LWS); O'Brien Institute for Public Health, University of Calgary, Calgary, Alberta,

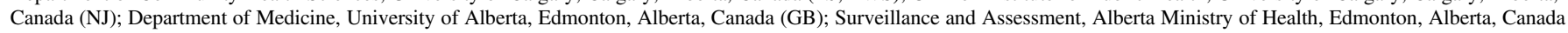

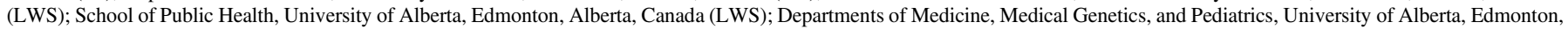

Alberta, Canada (OS).

Received March 27, 2015. Final Revisions Submitted August 28, 2015.

Correspondence to: Luanne M. Metz, Department of Clinical Neurosciences, University of Calgary, Foothills Hospital, 140329 Street NW, Calgary, Alberta, T2N 2T9, Canada.

Email: lmetz@ucalgary.ca 
Medical tourism is a growing industry in which people travel abroad to receive privately purchased medical care. ${ }^{1-3}$ It includes provision of not only evidence-based therapies but also experimental and unproven interventions. Many Canadians with multiple sclerosis (MS) have travelled internationally to have procedures for a putative condition called chronic cerebrospinal venous insufficiency (CCSVI). Despite a lack of evidence, they believed that CCSVI procedures would treat or even cure their MS. $^{4,5}$ The lack of a cure, and ineffective treatment for progressive MS, often leads to feelings of hopelessness. This makes many people susceptible to trying any therapy, including unproven options, that appears to offer a chance for a better future. ${ }^{6}$

The CCSVI hypothesis was proposed in 2009 by Dr. Paolo Zamboni. ${ }^{7,8}$ It suggests that insufficiency of the venous system (blocked veins) draining the brain and spinal cord increases venous pressure in the central nervous system, leading to parenchymal iron deposition that then triggers the perivenous inflammation seen in MS." Venous angioplasty, known to some as the "liberation therapy," was proposed to improve circulation and alleviate symptoms of MS, and perhaps cure it. Significant flaws to this hypothesis have since been published, ${ }^{10-16}$ and several studies have prospectively investigated this idea. ${ }^{5,77-22}$ Two meta-analyses found a positive correlation between MS and CCSVI, but both found extensive heterogeneity across the studies examined. ${ }^{23,24}$ The heterogeneity between studies was reduced to a nonsignificant level when studies whose authors have endorsed CCSVI therapy were excluded from the analysis. Conservative sensitivity analysis yielded no association between CCSVI and MS without any heterogeneity.

However, Zamboni's opinions, and the results of a pilot trial he conducted, were widely reported on Canadian television and in national newspapers in November 2009 as a "breakthrough" in the treatment of MS. These reports were accompanied by anecdotal stories of individuals who reported that their symptoms had improved dramatically after venous angioplasty. This stimulated unprecedented interest in CCSVI that spread quickly throughout the media and social media. However, limitations of the hypothesis and of the preliminary studies were rarely discussed. ${ }^{8,9}$ Also, since the initial media stories preceded publication of Zamboni's trials, these limitations could not be addressed immediately. Because angioplasty and venous stents were not available for CCSVI in Canada from a lack of evidence supporting the procedure, many Canadians left the country to have CCSVI procedures elsewhere. ${ }^{7}$

The increase in the number of people participating in medical tourism for unproven procedures such as those for CCSVI is causing growing concern about the potential dangers of this practice. These dangers include procedure complications, acquisition of infections caused by antibiotic resistant organisms, discontinuity of medical care, no plan or no availability for follow-up care, and even lack of communication about which procedures have been done. Also, informed consent may not meet Canadian standards. ${ }^{2}$ In spite of these concerns, there are significant gaps in our understanding of medical tourism. ${ }^{1,6,25,26}$ Much existing information about medical tourism is derived from speculation and anecdote. Additionally, most published studies of medical tourism are small and include heterogeneous patients with a variety of medical conditions who have undergone various interventions. ${ }^{1-3,27}$ Medical tourism for CCSVI involves a large number of individuals with a single condition, MS, in pursuit of the same unproven procedure. This homogeneous population provides us with the opportunity to determine if there are shared characteristics that make a person more likely to participate in medical tourism and also to explore their varied experiences. In this survey-based observational study, we describe a cohort of persons with MS, many of whom reported having CCSVI procedures and examine characteristics associated with the decision to engage in medical tourism.

\section{Methods}

\section{Setting and Recruitment}

The Alberta Multiple Sclerosis Initiative (TAMSI) is a longitudinal observational study of persons with MS living in the province of Alberta, Canada. The study was specifically designed to understand the characteristics of individuals who chose to seek procedures for CCSVI, and to determine the safety and patient-reported outcomes following these procedures. We obtained approval for the study from the Conjoint Research Ethics Board at the University of Calgary and the Heath Research Ethics Board at the University of Alberta. The study was launched on July 27, 2011, after an initial press release by the Ministry of Health encouraging all Albertans with MS to take part, irrespective of whether they had CCSVI procedures. ${ }^{28}$ Information about the study was also posted on the MS Society of Canada website $^{29}$ and mailed to all patients at the three MS clinics in Alberta and to the patients of most neurologists providing specialized MS care outside the MS clinics in tertiary care centers.

\section{Study Population}

Between July 2011 and March 2013, a convenience sample of 868 Albertans enrolled in TAMSI; follow-up continued until December 2013. We conducted a cross-sectional analysis of baseline data from $704(81.1 \%)$ eligible participants (Figure 1). Individuals were excluded from the analysis if they withdrew consent $(n=2)$ or did not complete the sociodemographic $(n=73)$ or clinical $(n=45)$ questionnaires. Nineteen individuals reported a CCSVI procedure date at the time of enrollment, but did not provide further details about their procedure. These individuals were excluded from this analysis because we were unable to determine their procedural status.

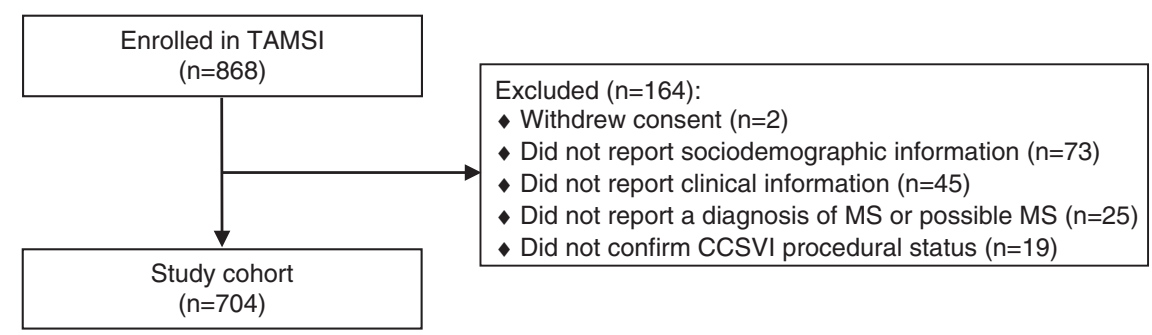

Figure 1: Selection of the TAMSI participants into the study cohort. 


\section{Data Collection}

Individuals self-registered at the publicly accessible www.tamsi.ca website that was set up exclusively for this study. Upon initial login, individuals read and agreed to the electronic consent form, which included consent for data linkage with several administrative and MS Clinic data sets. They then provided mandatory information including their email address, date of birth, Alberta personal health number, and residential postal code. Participants also reported their sex and date of their first CCSVI procedure (if applicable). They could update this information at any time. Most participants reported information about CCSVI procedures retrospectively because they enrolled in TAMSI after having the procedure. Online surveys were designed using the Feedback Server web application (http://www.dataillusion.com), a secure survey development and delivery tool that integrated with the TAMSI website. Participants could view a history of their completed surveys and a link to each survey assigned to them. Once completed, the survey link disappeared and participants could not view or change their responses. Paper versions of the baseline surveys were available upon request and were completed by 19 participants.

Patient-reported information included sociodemographic and clinical measures. Neighbourhood income quintile was derived by ranking the median family income of each dissemination area in Alberta from lowest to highest based on the 2006 Canadian census. Each study participant was assigned a quintile by linking their postal code to a dissemination area. Disability status was measured using the Patient Determined Disease Steps (PDDS). ${ }^{30}$ The PDDS is scored ordinally from 0 (no disability) to 8 (bedbound), and correlates well with the physician-scored Expanded Disability Status Scale. ${ }^{31}$ Participants also indicated the absence or presence of 23 comorbidities diagnosed by a physician.

Other patient-reported outcomes included the absence or presence of 18 common MS symptoms and their severity rated on a 10-point scale, the impact of fatigue using the Fatigue Impact Scale, ${ }^{32}$ current depressive symptoms using the Centre for Epidemiologic Studies Depression Scale, ${ }^{33}$ and health-related quality of life using the Multiple Sclerosis Quality of Life-54 and Health Utilities Index Mark 3 instruments. ${ }^{34,35}$ Because these symptoms and ratings were not obtained before participants had a CCSVI procedure, these data were not explored as factors associated with medical tourism.

Follow-up surveys to capture information about new procedures, provide updated opinions and symptom ratings, and complete standardized scales became available every 6 months after baseline until December 2013. Email reminders were sent at 6-month intervals to those who had incomplete surveys and to remind individuals to complete the follow-up surveys.

To measure public interest in medical tourism for CCSVI, we examined Google searches of the term "CCSVI" using Google Trends, a database of all Google searches that can be analyzed by month of access and region of user (https://www.google.ca/ trends/). This tool provides numbers that represent search interest relative to the highest number of searches in the time period and region under study and does not represent absolute search volume. The month with the highest number of searches is assigned the value 100; other months are scaled accordingly. Search data were analyzed between July 2009, 3 months before the CCSVI hypothesis spread throughout the media, and September 2014.

\section{Statistical Analysis}

Characteristics of the study cohort were summarized using frequency (percent), mean (standard deviation [SD]), and median (range) as appropriate. Missing responses were not imputed. To evaluate the generalizability of the study cohort to the underlying MS population, we compared participants' characteristics with a reference MS population consisting of 1717 MS patients recruited between May 2002 and March 2006 from the Calgary MS Clinic into an observational long-term study of risk factors associated with outcomes in MS. The reference population included 163 people $(9.5 \%)$ who also participated in TAMSI.

We describe the proportion of participants reporting medical tourism for CCSVI procedures and the location and timing of the procedure. Characteristics of participants who had procedures were compared with those who did not using chi-square tests, Fischer's exact tests, t-tests, or Wilcoxon rank-sum tests as appropriate. We evaluated factors associated with medical tourism for CCSVI procedures using binary logistic regression. Age at enrollment, sex, MS duration since onset, clinical course, disability status, and disease-modifying therapy (DMT) use were selected as predictors of interest. Because we had little information to guide our selection of covariates, marital status, highest level of education, employment status, neighbourhood income quintile, and number of comorbidities were included in the multivariable model if they were significant factors in univariate analysis. Age at enrollment and disease duration were categorized because these were nonlinearly related to the outcome. A detailed description of the variables analyzed and their coding is provided in Table S1. Goodness of fit of the multivariable regression model was evaluated using the Hosmer-Lemeshow goodness of fit test. We report odds ratios (ORs), 95\% confidence intervals (CIs), and two-sided $\mathrm{p}$ values for each variable in the final model. A statistically significant result was interpreted as $\mathrm{p}<0.05$. All analyses were performed with the statistical software package STATA, version 11.2 (StataCorp, 2009).

\section{Results}

\section{Characteristics of the Study Cohort}

Most study participants were women and Caucasian, and nearly half were employed (Table 1). The most common disease course was relapsing-remitting. Nearly half of participants were ambulatory and were currently using an MS DMT. Almost one-third of participants had previously been diagnosed with depression, whereas less than 5\% reported a previous diagnosis of diabetes mellitus, rheumatoid arthritis, or inflammatory bowel disease. As compared with the reference population, the TAMSI study cohort was slightly older at enrollment and a higher proportion drove an automobile. The TAMSI participants were also more likely to have a university education, to live in a neighbourhood with a higher median income, and to currently or previously use a DMT. They were similar to the reference population with regards to sex, ethnicity, marital status, employment status, living arrangements, family history of MS, age at MS onset, disability status, and the presence of specific comorbidities.

\section{Location and Timing of Medical Tourism for CCSVI Procedures}

Between April 2010 and September 2012128 (18.2\%, 95\% CI 15.4-21.2) participants traveled outside of Canada to obtain 
Table 1: Characteristics of the study cohort and a reference MS research population

\begin{tabular}{|c|c|c|c|c|c|}
\hline Characteristic & $\mathbf{n}$ & $\begin{array}{l}\text { Study Cohort } \\
\quad(\mathrm{n}=704)\end{array}$ & $\mathbf{n}$ & $\begin{array}{l}\text { 2002-2006 Calgary Research } \\
\text { Cohort* }(n=1717)\end{array}$ & p value \\
\hline Age at enrolment (years), mean $\pm \mathrm{SD}$ & 704 & $47.6 \pm 11.5$ & 1717 & $45.9 \pm 11.1$ & 0.0007 \\
\hline Sex, n (\%) women & 704 & $545(77.4)$ & 1717 & $1,324(77.1)$ & 0.87 \\
\hline Ethnicity, n (\%) Caucasian & 688 & $658(95.6)$ & 1697 & $1613(95.1)$ & 0.54 \\
\hline Marital status, n (\%) & 701 & & 1,709 & & 0.26 \\
\hline Single, never married & & $88(12.6)$ & & $182(10.6)$ & \\
\hline Married or common law & & $519(74.0)$ & & $1267(74.1)$ & \\
\hline Divorced, separated, or widowed & & $94(13.4)$ & & $260(15.2)$ & \\
\hline Highest level of education, $\mathrm{n}(\%)$ & 697 & & 1695 & & $<0.0001$ \\
\hline Less than high school diploma & & $32(4.6)$ & & $154(9.1)$ & \\
\hline High school diploma & & $170(24.4)$ & & $479(28.3)$ & \\
\hline College or trade certificate & & $268(38.5)$ & & $675(39.8)$ & \\
\hline Bachelor's degree & & $163(23.4)$ & & $288(17.0)$ & \\
\hline More than bachelor's degree & & $64(9.2)$ & & $99(5.8)$ & \\
\hline Employment status, n (\%) employed & 700 & $329(47.0)$ & 1640 & 847 (51.6) & 0.24 \\
\hline \multicolumn{6}{|l|}{ Neighbourhood income quintile (CAD), n (\%) } \\
\hline $21,312-26,461$ & 701 & $136(19.4)$ & 1596 & $279(17.5)$ & 0.04 \\
\hline $26,510-29,309$ & & $126(18.0)$ & & $304(19.1)$ & \\
\hline $29,431-32,365$ & & $140(20.0)$ & & $300(18.8)$ & \\
\hline $32,456-35,095$ & & $178(25.4)$ & & $490(30.7)$ & \\
\hline $35,353-50,681$ & & $121(17.3)$ & & $223(14.0)$ & \\
\hline Living arrangements, $\mathrm{n}(\%)$ private residence & 702 & $690(98.3)$ & 1714 & $1686(98.2)$ & 0.90 \\
\hline Driving ability, $\mathrm{n}(\%)$ drive an automobile & 697 & $587(84.1)$ & 1703 & $1340(78.7)$ & 0.002 \\
\hline Smoking status, $\mathrm{n}(\%)$ ever smoked & 700 & $555(79.3)$ & 1568 & $1082(69.0)$ & 0.46 \\
\hline Family history of MS, n (\%) first-degree relative & 668 & $100(15.0)$ & 1640 & $212(12.9)$ & 0.19 \\
\hline Age at MS onset (years), mean \pm SD & 659 & $33.3 \pm 10.2$ & 1668 & $33.0 \pm 10.0$ & 0.52 \\
\hline Disability status (PDDS), n (\%) & 704 & & 1701 & & 0.59 \\
\hline Normal or mild $(0-2)$ & & $339(48.2)$ & & $855(50.3)$ & \\
\hline Moderate (3-5) & & $226(32.1)$ & & $513(30.2)$ & \\
\hline Severe $(6-8)$ & & $139(19.7)$ & & $333(19.6)$ & \\
\hline DMT user, n (\%) & 692 & & 1678 & & $<0.0001$ \\
\hline Never & & $234(33.8)$ & & $938(55.9)$ & \\
\hline Former & & $122(17.6)$ & & $243(14.5)$ & \\
\hline Current & & $336(48.6)$ & & 497 (29.6) & \\
\hline Type of comorbidity present, n (\%) & 694 & & 1717 & & \\
\hline Depression & & $197(28.4)$ & & $525(30.6)$ & 0.29 \\
\hline Diabetes mellitus & & $27(3.9)$ & & $75(4.4)$ & 0.60 \\
\hline Rheumatoid arthritis & & $14(2.0)$ & & $33(1.9)$ & 0.88 \\
\hline Inflammatory bowel disease & & $13(1.9)$ & & $32(1.9)$ & 0.99 \\
\hline Bipolar disorder & & $7(1.0)$ & & $22(1.3)$ & 0.58 \\
\hline Suicide attempt in past year, $\mathrm{n}(\%)$ & 681 & $5(0.7)$ & 1717 & $14(0.8)$ & 0.84 \\
\hline
\end{tabular}

*A total of 1717 MS patients recruited between May 2002 and March 2006 from the Calgary MS Clinic into an observational long-term study of characteristics associated with outcomes in MS; $163 / 1717$ (9.5\%) of the 2002 to 2006 Calgary research cohort were also TAMSI participants.

Bold type indicates $\mathrm{p}$ value $<0.05$.

procedures for CCSVI. Three individuals travelled abroad twice for separate procedures. Participants traveled to the United States (42.0\%), Mexico (21.4\%), Costa Rica (11.5\%), and Poland (10.7\%); fewer traveled to Bulgaria, Germany, India, Jordan, or
Scotland (14.5\%). The frequency of individuals travelling abroad for their first CCSVI procedure declined over time: $80(62.5 \%$; 95\% CI, 54.5-70.9) in 2010, $40(31.1 \%$; $95 \%$ CI, 23.4-40.0) in 2011, and 8 (6.3\%; 95\% CI,2.7-11.9) in 2012. Only five 
individuals reported having procedures after enrolling in the study. Most participants underwent procedures for CCSVI during the year before study enrollment: mean (SD), 9.7 (5.8); median (interquartile range), 10 (7-13); and range 12 to 24 months before enrollment. Stratifying by the year of study enrollment also revealed a decline in CCSVI procedures over time. Among the 98 individuals who had procedures and enrolled in 2011, $63(64.3 \%)$ underwent procedures in $2010,33(33.7 \%)$ in 2011 , and $2(2.0 \%)$ in 2012. Similarly, among the 30 individuals who had procedures and enrolled in 2012, 17 (56.7\%) had procedures in 2010, $7(23.3 \%)$ in 2011, and $6(20.0 \%)$ in 2012.

\section{Factors Associated With Medical Tourism for CCSVI Procedures}

The results of the multivariable logistic regression analysis of factors independently associated with procedures for CCSVI are presented in Table 2. Medical tourism for CCSVI procedures was associated with longer disease duration, secondary progressive clinical course, and greater disability status. Participants reporting the onset of MS within the previous 5 years were less likely to undergo CCSVI procedures compared with those with longer disease duration; the linear relationship between disease duration and the odds of CCSVI procedures was not significant $\left(\chi_{\text {trend }}^{2}=0.21, p=0.65\right)$. CCSVI procedures were nearly three times more common among participants with a secondary progressive than a relapsing-remitting disease course but there was no difference between participants with primary progressive and relapsing-remitting MS. The odds of CCSVI procedures increased linearly with increasing level of disability (OR, 1.29; 95\% CI, 1.14-1.46 per unit increase on an 8-point scale; $\chi_{\text {trend }}^{2}=$ $15.59, \mathrm{p}=0.0001)$. Although not statistically significant in the multivariable analysis, CCSVI procedures were more common among men than women and among those reporting fewer comorbidities, and less common among those reporting osteoporosis (Table S2). Age at enrolment, employment status, and DMT use were not associated with having a CCSVI procedure after adjusting for covariates; marital status and neighbourhood income quintile were not significant factors in the univariate analysis.

\section{Sensitivity Analyses}

We evaluated the potential impact of selection bias using sensitivity analyses. First, we compared the characteristics of 704 participants included in the study cohort with 118 individuals excluded because they did not report sociodemographic or clinical information (Table S3). The two groups were similar with the exception that individuals with incomplete information were more likely to be men, to have less education, and to be current smokers. Next, we calculated the proportion of all enrolled individuals who reported having CCSVI procedures at any time during the study follow-up, regardless of whether or not they completed study questionnaires. A CCSVI procedure date was reported by 180 participants (20.7\%; 95\% CI, 18.1-23.6); 1 in 2009, $111(61.7 \%)$ in 2010, $57(31.7 \%)$ in 2011, and $9(5.0 \%)$ in 2012. Two people did not report the year of their CCSVI procedure. This was very similar to the main analysis. There was also no difference in the proportion of people who reported a CCSVI procedure amongst the few people who completed paper surveys $(15.8 \%)$.
Last, we evaluated the results of the logistic regression analysis with the addition of 19 individuals who reported a CCSVI procedure date but did not provide details to confirm their procedural status (Table S4). The overall results of the sensitivity analysis were similar to those from the main analysis (Table 2), with the exception that $\operatorname{sex}(p=0.03)$ became significantly associated with medical tourism for CCSVI procedures, whereas disease duration became marginally nonsignificant $(p=0.06)$. Additionally, in the sensitivity analysis, the magnitude of the OR was larger for the effects of clinical course and smaller for disease duration as compared to the main analysis; however, the CI levels overlapped.

\section{Discussion}

In this study, we characterized individuals with MS who sought the unproven CCSVI procedure outside Canada. Clinical factors suggesting a greater impact of MS on the affected individual including longer disease duration, a secondary progressive as compared to relapsing-remitting disease course, and more severe disability, were all associated with pursuit of the CCSVI procedure. Male sex was also associated with an increased likelihood to pursue the procedure but socioeconomic status was not.

Although all types of people with MS participated in medical tourism to have CCSVI procedures, the most important determinant of participation was greater disability. Male sex, unemployment, longer disease duration, and secondary progressive disease course are all associated with greater likelihood of disability and although all were statistically significant predictors of CCSVI procedures in the univariate model, the magnitude of association between these factors and having a CCSVI procedure were either partially or completely attenuated in the multivariable analysis. This supports the importance of disability as a driving factor. It is not surprising that people with greater disability are compelled to try any therapy that may be of benefit. Being a former user of a DMT was also associated with having a CCSVI procedure. This likely reflects greater disability because patients who fail to respond to MS DMT are likely to have greater disability and progressive MS. The perceived loss of therapeutic options may also play a role in deciding to have a CCSVI procedure. Longer disease duration and more severe disability have been found to be associated with increased use of complementary therapies or providers in those with MS. ${ }^{36,37}$.

The period of time during which TAMSI study participants engaged in medical tourism for CCSVI procedures was quite brief and was concurrent with the public's intense interest in CCSVI based on the Google Trends tool (https://www.google.ca/ trends/explore $\# \mathrm{q}=\mathrm{CCSVI} \& \mathrm{cmpt}=\mathrm{q} \&$ date $=7 / 2009+63 \mathrm{~m} \& \mathrm{geo}=\mathrm{CA})$ (Figure 2). Both CCSVI procedures and Google searches of "CCSVI" were rare in 2009, peaked in 2010 when $62.5 \%$ of CCSVI procedures were done in our cohort, became less common in 2011 when $31.1 \%$ of procedures were done, and became uncommon by 2012 when only $6.3 \%$ of procedures were done. Data collection for this study lagged about 1 year behind the trend and the first randomized controlled clinical trial of angioplasty for CCSVI in MS was published in June $2014 .{ }^{38}$ We speculate that medical tourism for procedures that do not provide value is likely to wane when expectations are not met, but a decrease in media interest may also have reduced patient interest. In the MS population, mass media sources are the first source of information for general health and MS concerns. ${ }^{39}$ The reasons for the interest 
Table 2: Logistic regression analysis of factors associated with medical tourism for CCSVI procedures

\begin{tabular}{|c|c|c|c|c|c|c|}
\hline \multirow[b]{2}{*}{ Predictor } & \multicolumn{3}{|c|}{ Univariate model } & \multicolumn{3}{|c|}{ Multivariable model* } \\
\hline & OR & $95 \% \mathrm{CI}$ & p value & OR & $95 \% \mathrm{CI}$ & $p$ value \\
\hline Age at enrollment (years) & & & 0.57 & & & 0.26 \\
\hline$<40$ & 1.00 & & & 1.00 & & \\
\hline $40-49$ & 1.08 & $0.63-1.85$ & & 0.66 & $0.35-1.25$ & \\
\hline $50-59$ & 1.17 & $0.69-1.98$ & & 0.49 & $0.24-0.99$ & \\
\hline$\geq 60$ & 1.51 & $0.83-2.75$ & & 0.59 & $0.24-1.42$ & \\
\hline Sex & & & 0.0002 & & & 0.05 \\
\hline Women & 1.00 & & & 1.00 & & \\
\hline Men & 2.20 & $1.45-3.33$ & & 1.64 & $0.99-2.70$ & \\
\hline Employment status & & & 0.002 & & & 0.86 \\
\hline Employed & 1.00 & & & 1.00 & & \\
\hline Unemployed & 1.87 & $1.25-2.79$ & & 0.95 & $0.56-1.62$ & \\
\hline Disease duration (years) & & & 0.001 & & & 0.02 \\
\hline$<5$ & 1.00 & & & 1.00 & & \\
\hline $5-9$ & 3.95 & $1.46-10.71$ & & 3.93 & 1.39-11.08 & \\
\hline $10-19$ & 6.42 & $2.49-16.57$ & & 4.67 & $1.70-12.83$ & \\
\hline$\geq 20$ & 4.64 & $1.76-12.20$ & & 3.29 & $1.12-9.68$ & \\
\hline Clinical course & & & $<0.0001$ & & & 0.03 \\
\hline RRMS & 1.00 & & & 1.00 & & \\
\hline SPMS & 4.04 & 2.51-6.50 & & 2.90 & $1.44-5.85$ & \\
\hline PPMS or PRMS & 2.51 & $1.39-4.55$ & & 1.67 & $0.72-3.86$ & \\
\hline Uncertain or possible MS & 1.40 & $0.71-2.76$ & & 1.85 & $0.81-4.24$ & \\
\hline Disability status (PDDS) & & & $<0.0001$ & & & 0.001 \\
\hline Normal (0) & 1.00 & & & 1.00 & & \\
\hline Mild (1-2) & 2.25 & $1.05-4.80$ & & 2.71 & $1.23-5.95$ & \\
\hline Moderate (3-5) & 3.66 & $1.83-7.32$ & & 3.35 & $1.54-7.30$ & \\
\hline Severe (6-8) & 8.27 & $4.10-16.70$ & & 5.99 & $2.46-14.58$ & \\
\hline DMT user & & & 0.0003 & & & 0.13 \\
\hline Never & 1.00 & & & 1.00 & & \\
\hline Former & 2.33 & 1.39-3.91 & & 1.92 & $1.02-3.60$ & \\
\hline Current & 0.90 & $0.57-1.43$ & & 1.47 & $0.76-2.85$ & \\
\hline Number of comorbidities & 0.86 & $0.74-1.00$ & 0.05 & 0.85 & $0.71-1.01$ & 0.07 \\
\hline
\end{tabular}

$*_{\mathrm{n}}=635 ; \mathrm{c}$-statistic $=0.76$; Hosmer-Lemeshow goodness of fit $\chi^{2}=4.99, \mathrm{p}=0.76$.

Bold type indicates the $95 \% \mathrm{CI}$ does not include the null value of 1 and $\mathrm{p}$ value $<0.05$.

in CCSVI procedures and the subsequent waning of interest deserve further exploration. It is hard not to be sympathetic to the preferences of people with such a devastating illness, but public funding of research based on a popular demand rather than science seems unwise when there are limited resources available.

It is notable that the most common place that study participants reported going for a CCSVI procedure was the United States. The availability of the procedure in the United States may also have been a driver of participation in medical tourism because Canadians may expect a higher standard of care in the United States compared with other countries offering CCSVI procedures and therefore may have felt safer having the procedure there. The availability of CCSVI in the United States may also have validated the procedure as valuable.
Limitations of this study should be considered. Although this study was not population-based, the TAMSI study population was representative of Albertans with MS who participated in a similar recent epidemiologic study with regards to sex, ethnicity, marital status, employment status, whether they lived in a private residence or not, family history of MS, age at MS onset, disability status, and the presence of any specific comorbidity. However, the TAMSI cohort was slightly older and participants were more likely to drive an automobile, have a university education, live in a neighborhood with a higher median income, and be a previous or current DMT user. The reference population participated in a study that used paper questionnaires and, although TAMSI participants could complete paper questionnaires, the study mainly promoted completion of online questionnaires. The online 


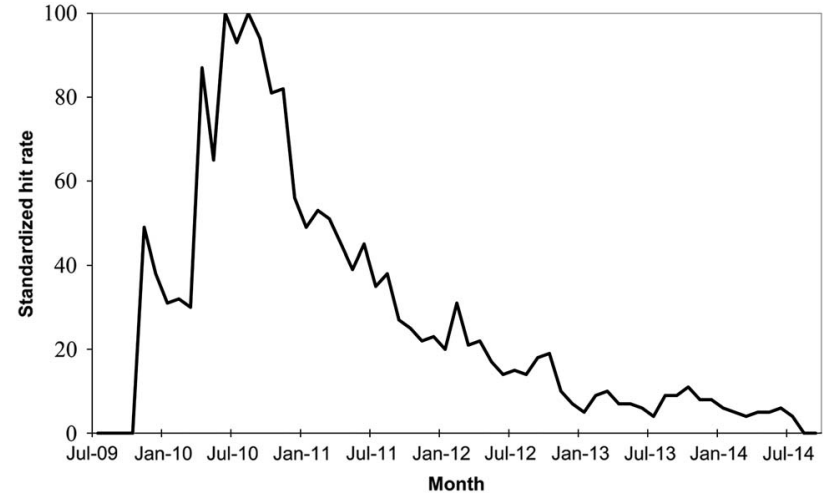

Figure 2: Frequency of Google searches for "CCSVI" between July 1, 2009, and September 30, 2014, in Canada.

survey method likely biased the TAMSI cohort toward inclusion of more educated participants with a higher income. The smaller proportion of people with university education amongst those who did not complete all the questionnaires suggests lack of familiarity with computer technology may have led to difficulty with participation. ${ }^{40}$ The higher proportion of TAMSI participants who were current or prior DMT users is likely partly because of the difference in the period when the studies were undertaken. The proportion of people in the Calgary MS Clinic who are using a DMT, or who formerly used a DMT, increases annually. As of August 1, 2011, when the TAMSI study began enrolment, $41.9 \%$ of Calgary MS Clinic patients were using a DMT and $14.1 \%$ were former users; this is more reflective of the TAMSI study participants in which $47.8 \%$ and $17.8 \%$ were current or former DMT users, respectively. The difference in age is quite trivial and unlikely to be meaningful but the slight difference in the proportion of participants who drive highlights the likelihood of unforeseen population differences when comparison groups are not determined by randomization; the significance of this difference is unclear. It is also possible that people with MS who were more interested in seeking CCSVI procedures were more likely to participate in TAMSI. All measures used in the study were self-reported, but we used a validated measure of disability, ${ }^{41}$ and the literature supports the ability of persons with MS to accurately classify their disease status and date of symptom onset. ${ }^{42}$ It is possible that we were unable to find a significant association between socioeconomic status and medical tourism for CCSVI procedures because we used an area-based measure as a proxy for participants' annual household income. The 2006 neighborhood income quintile may not reflect participant-level income during the study period, or the use of median income quintiles may have masked an effect among participants with the highest income. However, area-based measures of socioeconomic status show similar associations with health care utilization as individual level of measures. ${ }^{43}$

Finally, this study focused on medical tourism for one unproven procedure. We did not evaluate medical tourism for proven therapies in MS and do not know if the characteristics of those seeking such procedures differ from those seeking CCSVI procedures.

\section{Conclusions}

Our study provides an example of medical tourism that gained intense immediate interest mostly driven by the media but waned quickly. It illustrates that, although there was wide variation in people with MS that participated in medical tourism to have CCSVI procedures, the major driver of participation was greater disability. This highlights that for people with MS those with greater disability are the most vulnerable to unproven procedures that claim treatment or cure. It also highlights the lack of effective treatments for this stage of MS. Our study supports the importance of regulating the ability of practitioners to engage in such unproven procedures to protect vulnerable populations; this responsibility also lies with individual practitioners. We need to address the care of these individuals (symptom management, social support, desperation) and accelerate the search for effective DMTs in all stages of the disease, instead of investing money in a treatment fad.

\section{Disclosures}

GB has been a consultant and principal investigator and received consulting fees and grant support from Genzyme, Merck Serono, Novartis, and Teva Pharmaceutical Industries. KA has served as a consultant and received honoraria from Novartis and Biogen Idec. LM, JG, RAM, NJ, LS, WW, RD, and OS have nothing to disclose.

\section{SuPPlementary MATERIAL}

To view supplementary material for this article, please visit http://dx.doi.org/10.1017/cjn.2015.350

\section{ACKNOWLEDGEMENTS AND FUNDING}

This study was funded by a research grant from Alberta Health. NJ is the holder of a Canada Research Chair in Neurological Health Services Research and an Alberta Innovates Health Solutions Population Health Investigator Award.

\section{REFERENCES}

1. Johnston R, Crooks VA, Snyder J. "I didn't even know what I was looking for:" A qualitative study of the decision-making processes of Canadian medical tourists. Global Health. 2012;8:23.

2. Crooks VA, Turner L, Cohen G, et al. Ethical and legal implications of the risks of medical tourism for patients: a qualitative study of Canadian health and safety representatives' perspectives. BMJ Open. 2013;3:e002302.

3. Cameron K, Crooks VA, Chouinard V, Snyder J, Johnston R, Casey V. Motivation, justification, normalization: talk strategies used by Canadian medical tourists regarding their choices to go abroad for hip and knee surgeries. Soc Sci Med. 2014;106:93-100.

4. Baracchini C, Valdueza JM, Del Sette M, et al. CCSVI and MS: a statement from the European Society of neurosonology and cerebral hemodynamics. J Neurol. 2012;259:2585-9.

5. Chafe R, Born KB, Slutsky AS, Laupacis A. The rise of people power. Nature. 2011;472:410-1.

6. Holm C, Snyder J. "It was the best decision of my life:" a thematic content analysis of former medical tourists' patient testimonials. BMC Med Ethics. 2015;16:8.

7. Burton JM, Alikhani K, Goyal M, et al. Complications in MS patients after CCSVI procedures abroad (Calgary, AB). Can J Neurol Sci. 2011;38:741-6.

8. Zamboni P, Galeotti R, Menegatti E, et al. Chronic cerebrospinal venous insufficiency in patients with multiple sclerosis. J Neurol Neurosurg Psychiatry. 2009;80:392-9.

9. Zamboni P, Galeotti R, Menegatti E, et al. A prospective open-label study of endovascular treatment of chronic cerebrospinal venous insufficiency. J Vasc Surg. 2009;50:1348-58.

10. Benarroch EE. Brain iron homeostasis and neurodegenerative disease. Neurology. 2009;72:1436-40.

11. Zecca L, Youdim MB, Riederer P, Connor JR, Crichton RR. Iron, brain ageing and neurodegenerative disorders. Nat Rev Neurosci. 2004;5:863-73. 
12. Masuhr F, Einhäupl K. Treatment of cerebral venous and sinus thrombosis. In: Caso V, Agnelli G, Paciaroni M eds. Handbook on Cerebral Venous Thrombosis. Front Neurol Neurosci. Vol 23. Basel, Switzerland: Karger; 200:132-43.

13. Friedman DI, Jacobson DM. Idiopathic intracranial hypertension. J Neuroophthalmol. 2004;24:138-45.

14. Doepp F, Bähr D, John M, Hoernig S, Valdueza JM, Schreiber SJ. Internal jugular vein valve incompetence in COPD and primary pulmonary hypertension. J Clin Ultrasound. 2008;36:480-4.

15. Reekers JA, Lee MJ, Belli AM, Barkhof F. Cardiovascular and Interventional Radiological Society of Europe commentary on the treatment of chronic cerebrospinal venous insufficiency. Cardiovasc Intervent Radiol. 2011;34:1-2.

16. Crile G. Excision of cancer of the head and neck. With special reference to the plan of dissection based on one hundred and thirty-two operations. JAMA. 1906;47:1780-6.

17. Doepp F, Paul F, Valdueza JM, Schmierer K, Schreiber SJ. No cerebrocervical venous congestion in patients with multiple sclerosis. Ann Neurol. 2010;68:173-83.

18. Sundström P, Wåhlin A, Ambarki K, Birgander R, Eklund A, Malm J. Venous and cerebrospinal fluid flow in multiple sclerosis: a case-control study. Ann Neurol. 2010;68:255-9.

19. Auriel E, Karni A, Bornstein NM, Nissel T, Gadoth A, Hallevi H. Extra-cranial venous flow in patients with multiple sclerosis. J Neurol Sci. 2011;309:102-4.

20. Khan O, Filippi M, Freedman MS, et al. Chronic cerebrospinal venous insufficiency and multiple sclerosis. Ann Neurol. 2010; 67:286-90.

21. Wattjes MP, van Oosten BW, de Graaf WL, et al. No association of abnormal cranial venous drainage with multiple sclerosis: a magnetic resonance venography and flow-quantification study. J Neurol Neurosurg Psychiatry. 2011;82:429-35.

22. Baracchini C, Perini P, Causin F, Calabrese M, Rinaldi F, Gallo P. Progressive multiple sclerosis is not associated with chronic cerebrospinal venous insufficiency. Neurology. 2011;77:844-50.

23. Tsivgoulis G, Sergentanis TN, Chan A, et al. Chronic cerebrospinal venous insufficiency and multiple sclerosis: a comprehensive meta-analysis of case-control studies. Ther Adv Neurol Disord. 2014;7:114-36.

24. Laupacis A, Lillie E, Dueck A, et al. Association between chronic cerebrospinal venous insufficiency and multiple sclerosis: a metaanalysis. CMAJ. 2011;183:E1203-12.

25. Hopkins L, Labonté R, Runnels V, Packer C. Medical tourism today: what is the state of existing knowledge? J Public Health Policy. 2010;31:185-98.

26. Snyder J, Crooks VA, Johnston R, Kingsbury P. What do we know about Canadian involvement in medical tourism?: a scoping review. Open Med. 2011;5:139-48.

27. Turner L. News media reports of patient deaths following 'medical tourism' for cosmetic surgery and bariatric surgery. Deve World Bioeth. 2012;12:21-34.
28. Government of Alberta [Internet]. Alberta launches multiple sclerosis observational study. [updated 2011 Jul 27; cited 2014 Jun 4]. Available from: http://www.albertahealthservices.ca/5356.asp.

29. MS Society of Canada [Internet]. MS Update on: [updated $2011 \mathrm{Jul}$; cited 2014 Jun 4]. Available from: http://mssociety.ca/chapters/ calgary/pdf/MSUpdate_July11.pdf.

30. Hohol MJ, Orav EJ, Weiner HL. Disease steps in multiple sclerosis: a simple approach to evaluate disease progression. Neurology. 1995;45:251-5.

31. Marrie RA, Goldman M. Validity of performance scales for disability assessment in multiple sclerosis. Mult Scler. 2007;13:1176-82.

32. Fisk JD, Ritvo PG, Ross L, Haase DA, Marrie TJ, Schlech WF. Measuring the functional impact of fatigue: initial validation of the fatigue impact scale. Clin Infect Dis. 1994;18(Suppl 1):S79-83.

33. Weissman MM, Sholomskas D, Pottenger M, Prusoff BA, Locke BZ. Assessing depressive symptoms in five psychiatric populations: a validation study. Am J Epidemiol. 1977;106:203-14.

34. Vickrey BG, Hays RD, Harooni R, Myers LW, Ellison GW. A health-related quality of life measure for multiple sclerosis. Qual Life Res. 1995;4:187-206.

35. Feeny D, Furlong W, Boyle M, Torrance GW. Multi-attribute health status classification systems. Health Utilities Index. Pharmacoeconomics. 1995;7:490-502.

36. Marrie RA, Hadjimichael O, Vollmer T. Predictors of alternative medicine use by multiple sclerosis patients. Mult Scler. 2003; 9:461-6.

37. Shinto L, Yadav V, Morris C, Lapidus JA, Senders A, Bourdette D. Demographic and health-related factors associated with complementary and alternative medicine (CAM) use in multiple sclerosis. Mult Scler. 2006;12:94-100.

38. Siddiqui AH, Zivadinov R, Benedict RH, et al. Prospective randomized trial of venous angioplasty in MS (PREMiSe). Neurology. 2014;83:441-9.

39. Marrie AR, Salter RA, Tyry T, Fox JR, Cutter RG. Preferred sources of health information in persons with multiple sclerosis: degree of trust and information sought. J Med Internet Res. 2013;15:e67.

40. Smith AB, King M, Butow P, Olver I. A comparison of data quality and practicality of online versus postal questionnaires in a sample of testicular cancer survivors. Psychooncology. 2013;22: 233-7.

41. Learmonth YC, Motl RW, Sandroff BM, Pula JH, Cadavid D. Validation of patient determined disease steps (PDDS) scale scores in persons with multiple sclerosis. BMC Neurol. 2013;13:37.

42. Ingram G, Colley E, Ben-Shlomo Y, et al. Validity of patient-derived disability and clinical data in multiple sclerosis. Mult Scler. 2010;16:472-9.

43. Mustard CA, Derksen S, Berthelot J-M, Wolfson M. Assessing ecologic proxies for household income: a comparison of household and neighbourhood level income measures in the study of population health status. Health \& Place. 1999;5:157-71. 